\title{
TRANSIÇÃO SOCIALISTA EM MÉSZÁROS: “TRANSCENDER" / SUPERAR A MONTANHA - O TRABALHO ASSALARIADO, O CAPITAL E O ESTADO
}

\author{
Celeste Deográcias de Souza Bitencourt ${ }^{1}$
}

\begin{abstract}
RESUMO
A leitura do livro do filósofo húngaro István Mészáros, lançado no Brasil em 2015, A montanha que devemos conquistar: reflexões acerca do Estado, motivou-nos a apresentar nossas reflexões. Objetivamos expor nosso entendimento de que esse último título, ao centrarse na "crítica socialista radical do Estado", articula-se com toda a produção anterior do autor. Adotamos o procedimento de leitura e análise imanente do texto, apreendendo que o autor reafirma a perspectiva totalizante e radical que adota na abordagem não só dessa, mas também de várias outras temáticas candentes da vida humana, postas em relevo em suas obras. Compreendemos que sua "crítica radical dos fundamentos do Estado", insere-se no quadro de "crise estrutural global do sistema do capital". O autor analisa que essa crise atinge todas as principais instituições de reprodução do sistema, entre estas o Estado. A crise sistêmica ativa os limites absolutos insuperáveis na atual ordem social. Assim, transparece o anacronismo histórico do sistema do capital, cuja permanência é geradora de destruição em todos os âmbitos fundamentais do processo de produção e reprodução social. Ameaça a humanidade pelo desemprego estrutural; pelas guerras; pela produção destrutiva em si e das condições ambientais indispensáveis à reprodução da vida humana. Frente a estas desumanidades Mészáros defende que o desafio atual é "socialismo ou barbárie". Portanto, a necessidade e possibilidade da alternativa socialista demanda "conquistar" ("transcender"/superar) a "montanha" (entendida como o próprio sistema do capital em seus pilares: trabalho assalariado, capital e Estado) para implementar o projeto genuíno de Marx: do trabalho livremente associado, da erradicação do capital e fenecimento do Estado, ou seja, a superação de todas as "mediações de segunda ordem" impostas pelo sistema do capital. Concluímos que na perspectiva de Mészáros, para esse projeto ser bem sucedido, faz-se necessário uma teoria da transição socialista, e a ação consciente e organizada do Trabalho. Para tal, Mészáros contribui apresentando os princípios orientadores socialistas, e propõe a articulação de uma Nova Internacional, que organize e unifique a classe trabalhadora internacionalmente em torno de uma "ofensiva socialista".
\end{abstract}

PALAVRAS-CHAVE: Trabalho. Capital. Estado. Transição socialista. Emancipação Humana.

\begin{abstract}
Reading the book of the hungarian philosopher István Mészáros, published in Brazil in 2015 the mountain that we conquer: reflections on the state motivated us to present our reflections. We aimed to expose our understanding that this last title the focus on "critical radical socialist state" is articulated with all the author's previous production. We adopted the reading procedure and immanent analysis of the text apprehending the author reaffirms the totalitarian and radical perspective that adopts the approach not only this, but also several other burning issues of human life, put into relief in his works. We understand that his "radical critique of the foundations of the state" is within the framework of "global structural crisis of the capital system." The author analyzes this crisis affects all the main breeding institutions of the

\footnotetext{
${ }^{1}$ Doutora pela Faculdade de Educação (UFMG). Professora da Educação Básica da Prefeitura Municipal de Betim em Minas Gerais. E.mail: celdeminasfae @ yahoo.com.br
} 
system, among them the State. The active systemic crisis the absolute insurmountable limits in the current social order. So transpires the historical anachronism of the capital system, whose stay generates destruction in all key areas of the production and social reproduction process. Threatens humanity by structural unemployment; by wars; by destructive production itself and the environmental conditions essential for the reproduction of human life. Against these inhumanities Mészáros advocates that the current challenge is "socialism or barbarism". Therefore, the need and possibility of socialist alternative demand "conquer" (transcending / overcome) the "mountain" (understood as the capital system itself on its pillars: alienated labor, capital and state) to implement genuine project of Marx: the freely associated labor, the abolition of capital and withering away of the state, ie the abolition of all "mediations second order" imposed by the capitalist system. We conclude that in Mészáros perspective, for this project to be successful, a theory of socialist transition it is necessary, and the conscious and organized action of Labor. For this, Mészáros contributes presenting the socialist guiding principles and proposes the articulation of a New International, to organize and unify the working class internationally around a "socialist offensive".

KEYWORDS: Work. Capital. State. Socialist transition. Human emancipation.

\section{INTRODUÇÃO}

A matriz analítica da vasta obra de István Mészáros situa-o como um dos maiores filósofos marxista da atualidade. Encontra-se em plena atividade intelectual, mesmo tendo se aposentado em 1995, das atividades docentes na Universidade de Sussex, Inglaterra (onde reside desde 1959, quando teve que migrar da Hungria por participar do Levante Húngaro de 1956), na qual recebeu o título de Professor Emérito de Filosofia.

Produz uma densa, sólida, rigorosa e polêmica obra, na qual realiza uma "síntese decisivamente inspirada em Marx". Esta se apresenta in statu nascendi em sua Teoria da Alienação em Marx (2006) onde indica que "a alienação do trabalho" é a raiz causal de todo um "complexo de alienações". Mas, como apresenta-nos Antunes (2002) "é também tributário, por um lado, da matriz ontológica de Lukács (com quem dialoga e polemiza ${ }^{2}$ fortemente em vários momentos)". Assim a originalidade de sua obra "devassa o passado recente e o nosso presente, oferecendo um manancial de ferramentas para aqueles que estão olhando para o futuro. Para além do capital.” (ANTUNES, 2002, p. 20).

Como alerta-nos o próprio Mészáros (2007) a gravidade e complexidade dos problemas não nos deixam "espaço para tranquilidade ou certeza", caso "os desafios históricos postos diante do movimento socialista não sejam enfrentados com sucesso, enquanto ainda há tempo". Por isso, enfatiza, reiterando as "palavras dramáticas de Rosa Luxemburgo" que o século a nossa frente deverá ser o século do "socialismo ou barbárie", às

\footnotetext{
${ }^{2}$ Cf. As posições de Mészáros sobre Lukács em Para além do capital: rumo a uma teoria da transição (2002), particularmente os Capítulos 6 a 10 e também em $O$ conceito de dialética de Lukács (2013).

\begin{tabular}{l|l|l|l|l|}
\hline Rovista Dialectus & Ano 2 & n.7 & Setembro - Dezembro 2015 & p. 48 - 67
\end{tabular}
}


quais acrescenta a frase "barbárie se tivermos sorte", uma vez que "o extermínio da humanidade é um elemento inerente ao curso do desenvolvimento destrutivo do capital" (MÉSZÁROS, 2007, p. 132), tal como evidenciam as imensas desumanidades, em todos os âmbitos da vida, provocadas pela produção destrutiva em si e dos meios da existência humana e das permanentes e injustificadas guerras.

Esta assertiva está consubstanciada na obra de Mészáros (2002) na qual realiza um intenso enfrentamento teórico-prático, no sentido de contribuir, com o processo de emancipação humana. Sua análise crítica dá-se não só no sentido de negar a atual ordem social, mas é principalmente, afirmativa e propositiva ao indicar-nos os princípios orientadores de uma teoria da transição socialista, na qual uma de suas teses centrais é, e tratada com destaque, a necessidade da "ofensiva socialista".

Ao analisarmos a abrangência da perspectiva de Mészáros, não consideramos adequado restringi-lo a um pessimista. Mesmo que, já por quase cinco décadas, reitera em suas análises que vivemos em uma "nova época histórica" que se configura por uma "crise estrutural do capital", cuja gravidade nos "deixa prever a potencial autodestruição da humanidade", caso prevaleçam as tendências da ordem atual. Mas obstinadamente, e por igual tempo, também se empenha em alertar-nos que, para superar tal realidade, os "remédios potenciais" têm que ser "globais" e "apontar para uma ordem social qualitativamente diferente em que deixam de existir as tendências destrutivas, hoje dominantes, de crescimento canceroso e acumulação de capital”. (MÉSZÁROS, 2004, p. 15-16).

Como testemunha toda a sua obra, nosso autor insiste na máxima de "socialismo ou barbárie", optando nitidamente pela perspectiva socialista, por analisar a realidade em termos de "tendências", "possibilidade" e "necessidade" e não como "determinações mecânicas". Acredita ainda, que se "tomarmos seriamente 'a responsabilidade dos intelectuais", todo intelectual crítico, não pode abdicar de seu fundamental "papel na transformação social positiva, da qual necessitamos tão urgentemente". Considera que não pode "haver justificativa para a omissão". Mesmo havendo uma "conexão objetiva" entre a "dinâmica da confrontação histórica em curso entre capital e trabalho", que força o trabalho a "assumir uma postura defensiva", e a uma postura negativa por parte de muitos intelectuais que se "tornam introvertidos, evasivos e desorientados". Nesse sentido, a adesão ao "lamentável conto da pósmodernidade" é para Mészáros (2006a, p. 17) bem ilustrativo.

Diferentemente da "debandada" que acometeu muitos intelectuais da esquerda e contrariamente a outros tantos, que tentaram demonstrar a inviabilidade do pensamento

\begin{tabular}{|l|l|l|l|l|}
\hline Qevista Dialectus & Ano 2 & n.7 & Setembro - Dezembro 2015 & p. $48-67$ \\
\hline
\end{tabular}


marxiano, Mészáros (2006, p. 25) afirma sua convicção na possibilidade e necessidade de um projeto socialista. Pois, considera que o sistema do capital esgotou suas potencialidades civilizatórias, e está sendo abalado em seus "fundamentos como sistema mundial”.

Indica-nos, ainda, que se já vivenciamos a "barbárie" em largos traços, já o "socialismo", não é algo inevitável e mecânico, e só pode ser obra de um vigoroso e consciente movimento da classe trabalhadora organizado internacionalmente. Firme nessa convicção, Mészáros (2014, p. 67-90) em suas Reflexões sobre a Nova Internacional, expõenos os princípios orientadores que nortearam Marx a fundar a I Internacional e propugna que em nosso tempo "a constituição e operação bem sucedida de uma Nova Internacional não é apenas dolorosamente óbvia, mas também extremamente urgente". E numa perspectiva, nada pessimista, mas positiva e propositiva, quanto a esse projeto diz que "pela primeira vez na história do movimento internacional combativo da classe trabalhadora - única alternativa hegemônica factível em relação ao capital - pode ser realizado". (MÉSZÁROS, 2014, p. 84).

Alerta ainda, que para o projeto dessa nova ordem ser vitorioso, faz-se necessário realizar um "reexame autocrítico das experiências revolucionárias passadas" e elaborar os "princípios orientadores de uma teoria da transição socialista", empenho que está manifesto como subtítulo: rumo a uma teoria da transição, da sua grande obra Para além do capital. Perspectiva que explicita nos capítulos deste e de seus vários outros livros. Assim, achamos mais apropriado pensarmos de acordo com Mészáros, quando diz que "não podemos ter medo de defender o que Daniel Singer chama de 'utopia realista'. Pois, 'se toda tentativa de mudar a sociedade, e não apenas remendá-la, é classificada com raiva e desprezo de utópica, então, transformando o insulto numa medalha de honra, devemos proclamar que somos todos utópicos"”. (MÉSZÁROS, 2004, p. 16).

Acreditamos que para melhor apreendermos a complexidade da elaboração teórica de Mészáros, devemos orientar-nos pelo procedimento que o próprio Mészáros adota quando realiza o estudo das obras marxianas. Ele afirma a "exigência de nos orientarmos pelo espírito de sua obra", de que se deve "desejar entender", e "propriamente entender" a proposição do autor, para depois criticar. Pois, segundo Mészáros "tornou-se moda, ser crítico de Marx" (e de qualquer autor, ou do próprio Mészáros), sem antes entender o projeto teórico do autor e "pelo espírito da sua obra". E a crítica quando couber e no que couber, deve ser feita entendendo o "contexto e as limitações dialéticas vitais de suas afirmações" (MÉSZÁROS, 2002, p. 520) se possível, deve ser propositiva e visar como Mészáros (2002) Para além do 
capital: rumo a uma teoria da transição socialista, e o horizonte marxiano de uma sociedade comunista.

A originalidade do pensamento marxiano deve-se aos seus fundamentos ontológicos e a compreensão dos seus lineamentos deve ser buscada nos textos do próprio autor, como afirma Souza Junior (2015) ao sistematizar sobre o procedimento metodológico marxiano, no qual

\footnotetext{
a razão dialética se refere, simultaneamente, a uma determinada racionalidade objetiva imanente ao processo da realidade e a um sistema categorial capaz de reconstruir (ideal e subjetivamente) esta processualidade, que entendemos a possibilidade de uma apreensão intelectiva dos objetos postos à análise. (SOUZA JUNIOR, 2015, p. 151).
}

Ainda, em Souza Junior (2011) posicionamos quanto à distinção entre a perspectiva ontológica marxiana e as perspectivas gnosiológicas de análise da realidade social. Nessa elaboração indicamos que a "perspectiva ontológica busca entender, como o em si pode ser capturável em sua integridade. Esta é, em termos ontológicos, a questão fundamental do método". (SOUZA JUNIOR, 2011, p. 31).

Quanto a esse procedimento, referenciamos-nos, ainda, nas considerações de Chasin (2009), sendo esta também, uma fonte importante a ser consultada, pois, fornece-nos a indicação de uma correta apreensão de um texto. Diz-nos que a "postura analítica deve propender ao compromisso com a solidez dos vigamentos que caracterizam a chamada análise imanente ou estrutural”. O analista deve procurar apreender os "nexos ou significados efetivos", e assim, na "melhor tradição reflexiva", deve encarar o texto - $a$ formação ideal - em sua textura significativa em si mesma, "aí compreendida toda a grade de vetores que o conformam, tanto positivos como negativos: o conjunto de suas afirmações, conexões e suficiências, como também as eventuais lacunas e incongruências que o perfaçam”. A leitura e análise devem de forma radical ter respeito "à estrutura e à lógica inerente ao texto examinado, ou seja, que tem por mérito a sustentação de que antes de interpretar ou criticar é incontornavelmente necessário compreender e fazer prova de haver compreendido". (CHASIN, 2009, p. 25 - 26).

\section{MÉSZÁROS PERSPECTIVA “TRANSCENDER” A MONTANHA}

Seguindo, então, os lineamentos do texto de Mészáros (2015, p. 15-30) percebemos que, já nas páginas introdutórias de A montanha, o autor situa sua análise "crítica radical do Estado, no espírito marxiano, com implicações de longo alcance para o fenecimento do

\begin{tabular}{|c|c|c|c|c|}
\hline Rovista Dialectus & Ano 2 & n.7 & Setembro - Dezembro 2015 & p. $48-67$ \\
\hline
\end{tabular}


próprio Estado" e tendo em vista um conjunto de "considerações" apontadas nessa e em outras obras.

Assim, estas "considerações" e a motivação de Mészáros fundamentam-se na perspectiva marxiana, ainda não efetivada de que "o Estado (e a política em geral, como um domínio separado) deve ser transcendido, por meio de uma transformação radical de toda a sociedade". Considera que essa transformação "não pode ser simplesmente uma revolução política"; mas “deve ser uma revolução social”, que para ser "bem-sucedida não pode ser local ou nacional", pois, apenas "revoluções políticas podem se confinar a uma situação limitada, de acordo com sua própria parcialidade", por isso, o caráter negativo da política, contraposto à positividade da revolução social, em seu caráter "global/universal", o que implica a "transcendência necessária do Estado em escala global". Assim, adverte-nos que os elementos da teoria marxiana constituem, claramente, um "todo orgânico e não podem ser separados um a um, pois cada um se refere a todos os demais e só adquirem seu significado pleno graças as suas interconexões recíprocas”. (MÉSZÁROS, 2015, p. 120-122).

$\mathrm{Na}$ Introdução o autor demonstra, ainda, que seu projeto articula-se a um conjunto de difíceis questões teórico-práticas que "devem ser respondidas hoje” e leva-nos a refletir sobre

O que está acontecendo em nosso lar planetário nos críticos tempos atuais? Por que as soluções tradicionais do Estado não conseguem produzir os resultados esperados? O Estado, tal qual constituído historicamente, é mesmo capaz de resolver todos os nossos graves problemas ou o Estado como tal tornou-se um dos principais contribuintes para o agravamento de seus próprios problemas e para sua insolubilidade crônica? Quais são os requisitos de uma alternativa radicalmente diferente? Existem quaisquer perspectivas viáveis para o futuro, caso uma forma substancialmente diferente de controlar o metabolismo social não possa ser instituída em oposição à preponderância das perigosas determinações do Estado em falência? Existe uma saída do círculo vicioso ao qual estamos confinados pelas determinações estruturais incorrigíveis de controle sociometabólico do capital no domínio reprodutivo material e no âmbito de suas formações estatais necessárias?. (MÉSZÁROS, 2015, p. 15-16).

Entendemos que essas questões apontam para as preocupações que movem as reflexões de Mészáros e articulam-se, não só com as inúmeras elaborações do autor, mas também com o procedimento teórico-metodológico que adota em suas obras, rigorosamente matrizado pela ontologia presente nas elaborações marxianas. Da nova filosofia e ciência instaurada por Marx, de não só interpretar o mundo, mas também transformá-lo, de não só compreender as "formas de ser, as determinações de existência” (MÉSZÁROS, 2015, p. 101),

\footnotetext{
${ }^{3}$ Neste livro, essa é a temática central do Capítulo 2 - O "fenecimento" do Estado? E está presente também no Capítulo 7 e Apêndice 1 - Como poderia o Estado fenecer?

\begin{tabular}{|l|l|l|l|l|}
\hline Q Rovista Dialectus & Ano 2 & n.7 & Setembro - Dezembro 2015 & p. 48 - 67 \\
\hline
\end{tabular}
}


mas também apreender as possibilidades de sua "transcendência/superação". (MÉSZÁROS, 2015, p. 99; 109; 114; 120).

Aqui, nos parece muito importante relembrar o alerta que Mészáros (2006, p. 17 - 28) faz-nos de que para compreendermos a "unidade e a coerência interna" do pensamento e da visão de mundo de Marx é fundamental entendermos que "toda a estrutura da teoria de Marx é dialética, seus conceitos fundamentais simplesmente não podem ser entendidos fora da inter-relação dialética". Aliás, entendemos que esse mesmo procedimento pode e deve ser adotado na leitura de Mészáros. O autor chama nossa atenção, ainda, para a complexidade na tradução de "palavras-chave" como "transcendência" (Aufhebung), que "tem conotações muito diferentes no texto original" e, no alemão significa ao mesmo tempo "transcendência", "supressão", "preservação" e "superação (ou substituição) pela elevação a um nível superior". (MÉSZÁROS, 2006, p. 18).

Para Mészáros, “Aufhebung”- transcendência/superação - é um conceito-chave e “deve situar-se no centro de nossas atenções" por vários motivos. Pois "a inversão da relação estrutural dos conceitos", "desorientou todos os comentaristas" ao interpretar conceitoschaves como esse e "em muitos casos com graves deformações do sistema de Marx como um todo". E como "evidentemente, nenhum conceito pode ser elucidado por si mesmo", em especial "esse conceito de 'transcendência (Aufhebung) da auto-alienação do trabalho' fornece a ligação essencial com a totalidade da obra de Marx". Também porque no “desenvolvimento do marxismo após a morte de seus fundadores, o tema foi muito negligenciado e, por motivos históricos compreensíveis, o marxismo recebeu uma orientação mais diretamente instrumental”. (MÉSZÁROS, 2006, p. 17-28).

De acordo com Mészáros, (2006, p. 19) “o leitor deve lembrar-se constantemente de que está lidando com complexidades de uma estrutura de discurso dialética" onde cada "microcosmo é um macrocosmo" em suas "múltiplas interligações dialéticas" ou, mesmo das suas "interligações estruturais fundamentais" ou ainda, da "reciprocidade dialética" entre a base material objetiva e a superestrutura geral.

Nestes termos que, para Mészáros se a "teoria marxiana do Estado" fosse inválida, "o marxismo como um todo se tornaria completamente insustentável, em vista da centralidade" que a "reciprocidade dialética entre base e superestrutura, entre as fundações materiais da sociedade e sua esfera política" tem na teoria de Marx (MÉSZÁROS, 2015, p. 113 - 115). E no sistema do capital ela comparece em um "círculo vicioso", na "forma de uma dialética atrofiada", como "contradições fundamentais, que não podem ser ignoradas", pois o recíproco

\begin{tabular}{|c|c|c|c|c|}
\hline Revista Dialectus & Ano 2 & n.7 & Setembro - Dezembro 2015 & p. $48-67$ \\
\hline
\end{tabular}


"intercâmbio alienado entre os domínios material/econômico e político do sistema do capital" domina o trabalho. (MÉSZÁROS, 2015, p. 107).

Esta "reciprocidade dialética" entre base e superestrutura, para Mészáros, é de "vital importância" para a compreensão da teoria de Marx. Pois, relaciona-se diretamente com o “doloroso fracasso histórico em alcançar qualquer progresso até o momento em direção ao fenecimento do Estado, tal qual vislumbrado por Marx" e, por conseguinte, com a perspectiva da "emancipação humana em termos verdadeiramente universais e em termos substantivamente equitativos”. (MÉSZÁROS, 2015, p. 92-94).

Relaciona-se, portanto, diretamente com os processos produtivos e reprodutivos da vida humana, da emancipação do trabalho do jugo do capital e do Estado. Pois, hoje no sistema do capital, mesmo com o desemprego estrutural, Estado e capital acordam sobre a redução da jornada de trabalho, só em prejuízo para o trabalhador e "a serviço da acumulação de capital e da maximização do lucro". Relaciona-se, também com a "categoria crucial do tempo disponível" que, para tornar-se um "princípio orientador para a regulação da reprodução social" implica a "criação de uma ordem social radicalmente diferente". Esse princípio para efetivar-se demanda "um modo de tomada de decisão na qual a escolha autônoma dos objetivos dos indivíduos livremente associados possa ser combinada com uma estrutura geral racionalmente planejada e historicamente sustentável e possa ser verdadeiramente integrada nela”. (MÉSZÁROS, 2015, p. 96; 109).

A reciprocidade entre base e superestrutura "diz respeito à relação entre a forma como reproduzimos nossas condições materiais diretas de vida através das horas que dedicamos todos os dias ao trabalho em comparação com as horas que alocamos para outras atividades". E a "questão vital do papel do Estado" entra em cena, também, e precisamente nesse ponto, pois o "processo de reprodução social geral, com a multiplicidade de suas ações produtivas materiais e de várias iniciativas de tomadas de decisão, deve coerir de alguma maneira, caso contrário, a sociedade em questão não poderia sobreviver”. (MÉSZÁROS, 2015, p. 93).

E na "ordem sociometabólica de reprodução" regida sob o domínio do capital, "essa coesão é possível somente se a dimensão de controle político geral se constituir como órgão de tomada de decisão separado/alienado de algumas das funções mais vitais". Assim, que a "função vital" das "formações de Estado do sistema do capital" é agir como "corretivos necessários", pelo menos enquanto forem historicamente capazes de cumprir tais "funções corretivas" para alguns "defeitos estruturais identificáveis na própria natureza das estruturas reprodutivas materiais". A constatação desta realidade, como alerta Mészáros, tem "duas 
importantes conseqüências" para o projeto socialista. Tanto na avaliação do passado, como indicado, por não ter cumprido com as expectativas originais de "fenecimento do Estado". (MÉSZÁROS, 2015, p. 94).

Mas, tem implicações também no presente, para a "crítica radical do Estado do capital" frente ao seu "fracasso histórico em cumprir suas funções corretivas" vitais. E por ser cada vez mais impossibilitado de cumpri-las, mediante a crise estrutural que só se avoluma, para a qual não tem soluções, além de ainda, por suas intervenções, colocar em "perigo o processo metabólico social geral". Isto porque o Estado sendo "parte integral das determinações estruturais do sistema do capital", não pode "eximir-se da crise estrutural em desdobramento do sistema do capital como um todo". (MÉSZÁROS, 2015, p. 94).

Essas conseqüências se reverberam também nas prospecções para o futuro, pois é “impossível vislumbrar o necessário fenecimento do Estado sem, simultaneamente, confrontar também os problemas críticos de alterar radicalmente o processo de reprodução material global". Ou seja, considerando que em Marx a "primazia relativa nessa inter-relação inextrincável entre as estruturas reprodutivas materiais do capital e suas formações de Estado - que em um determinado ponto da história torna-se um ciclo vicioso - pertence às primeiras", o fenecimento do Estado, requer a erradicação do trabalho assalariado e do capital. Ainda, nos termos de Mészáros, de todas as "mediações de segunda ordem" do sistema do capital. (MÉSZÁROS, 2015, p. 94).

Aqui, também, nos parece elucidativo atentar para a visão que Mészáros apresentanos, em outro texto, para o qual

O Estado moderno não foi formado como resultado de alguma determinação econômica direta, como um afloramento superestrutural mecânico, em conformidade com uma visão reducionista da supostamente unidimensional dominação material da sociedade, tal qual apresentado pela concepção marxista vulgar de tais questões. Pelo contrário, foi constituído dialeticamente por meio de sua necessária interação recíproca com a base material altamente complexa do capital. Nesse sentido, o Estado não foi apenas moldado pelas fundações econômicas da sociedade, como também moldou de forma bastante ativa a realidade multifacetada das manifestações reprodutivas do capital no decorrer de suas transformações históricas, tanto ascendente como na fase descendente de desenvolvimento do sistema do capital. (MÉSZÁROS, 2011b, p. 235).

Para apreendermos mais profundamente a "problemática da 'reciprocidade' e 'correspondência' dialética", da concepção marxiana de base e superestrutura, isto é - "como

${ }^{4}$ Cf. Mészáros (2002, p.180) onde o autor esclarece-nos detalhadamente sobre as "mediações de segunda ordem" do sistema do capital. 
um complexo integrado de determinações materiais e ideais, com a prioridade última conferida à primeira", para não incorremos em "alguma concepção estrutural-funcionalista", indicamos, também, como importante fonte de consulta e análise, o Capítulo 3 - Conceitoschave na dialética da base e superestrutura de Mészáros. (2011c, p. 63-103).

Pois, nele o autor alerta-nos para tomarmos cuidado com a apresentação "telegráfica" da "interconexão dialética entre base e superestrutura" como apresentada por Marx no "Prefácio de 1859". Mészáros considera que esta "breve" e "concisa" citação, não pode, "de modo algum, ser considerada um substituto adequado para suas visões cuidadosamente qualificadas e 'matizadas', conforme formuladas em diversos livros, artigos e cartas". Enfatiza que, sobre a complexa "discussão de base e superestrutura", as "notáveis proposições” de Marx, expostas no “"Prefácio' de 1859 em si só adquirem seu significado apropriado se lidas em conjunção com a análise de alguns outros grandes aspectos da mesma problemática, ao passo que sem essa leitura é-se tentado a atribuir uma intenção mecânica à tão citada passagem”. (MÉSZÁROS, 2011c, p. 67).

Por isso, essas "categorias-chave", só podem ser compreendidas, quando se leva em "conta pelo menos os principais argumentos nos termos dos quais seu autor tenta articula-las". O que demanda, segundo Mészáros, que nos familiarizemos "com algumas dimensões negligenciadas da explicação de Marx", sobre a reciprocidade dialética entre essas categoriaschave, “que sequer são aludidas no 'Prefácio', - antes de podermos realmente apreciar ou questionar o valor explicativo da 'base e superestrutura"” (MÉSZÁROS, 2011c, p. 67).

Mészáros esclarece-nos que é central, fundamental e mesmo necessário, que nos concentremos na "distinção" que Marx realiza entre "superestrutura enquanto tal" e a superestrutura jurídica e política específica. Onde o "todo da superestrutura, até mesmo suas dimensões mais mediadas (crenças religiosas, práticas artísticas, concepções filosóficas)" foi "constituída e articulada dentro do quadro de costumes e tradição bem antes" dessa superestrutura geral, em seu curso de desenvolvimento histórico, poder assumir a forma característica de 'superestrutura jurídica e política' e na “forma apropriada a vários modos de reprodução 'ordenada' dentro dos confins da divisão hierárquico-estrutural do trabalho" com todo o resto devendo se sujeitar as "suas determinações, embora, obviamente, no sentido dialético". Assim que, a "proeminência das determinações jurídicas e políticas no exercício das funções essenciais do metabolismo social é característica das sociedades de classe, incluindo o longo período histórico de transição da formação social capitalista para a 'fase superior da sociedade socialista' (ou comunista)" (MÉSZÁROS, 2011c, p. 94 - 95).

\begin{tabular}{|l|l|l|l|l|}
\hline Qovista Dialectus & Ano 2 & n.7 & Setembro - Dezembro 2015 & p. $48-67$ \\
\hline
\end{tabular}


Portanto, para Mészáros, devemos atentar para a existente "distinção marxiana" entre

superestrutura enquanto tal e o conceito mais limitado de "superestrutura jurídica e política", que se refere a determinações e condições sóciohistóricas qualitativamente diferentes. Os dois conceitos frequentemente são irremediavelmente fundidos, carregando consigo a falha em fazer a necessária distinção e uma tendência a oferecer explicações e interpretações mecânicas completamente implausíveis. Pois somente com referência à transformação historicamente constituída, e, em um certo estágio de desenvolvimento social, antagonisticamente determinada, da superestrutura em uma esfera separada e cada vez mais alienada de dominação jurídica e política é que algumas das idéias seminais de Marx - inclusive sua crítica radical da política em si - podem se tornar de fato intelegíveis. (MÉSZÁROS, 2011c, p. 67).

Neste sentido, para Mészáros (2006) é compreensível que, para o marxismo que negligenciou Marx, tal como para a filosofia que foi dominada por "várias tendências de empirismo e formalismo positivistas", vários "conceitos usados por Marx - talvez a maioria de seus conceitos fundamentais" - pareçam "estranhos, ou talvez mesmo totalmente sem significado ou autocontraditórios, a todos os que estão habituados à enganosa 'simplicidade do senso comum' do empirismo positivista, ou à clareza esquemática e linear do formalismo filosófico, ou a ambos”. (MÉSZÁROS, 2006, p.18).

Mészáros recupera em Marx, vários outros aspectos, que declara relevantes e fundamentais para a alternativa socialista, mas que foram negligenciados pelo marxismo, com conseqüências desastrosas para o movimento emancipatório da classe trabalhadora. Como atestam os desdobramentos das experiências revolucionárias do século XX, que, por exemplo, ao não considerar a distinção entre capital e capitalismo, erraram o alvo ao apenas "derrubar o capitalismo", mantendo intacto o tripé: Trabalho assalariado, Capital e Estado, não consubstanciando-se, assim, uma transição socialista.

Percebemos que, n'A Montanha, Mészáros adota um procedimento que é perceptível em suas outras obras. Ao abordar as categorias, geralmente, inicia apresentando-nos como cada uma é compreendida e tematizada pelo ponto de vista burguês ${ }^{5}$. Em contraposição apresenta-nos uma análise do ponto de vista do real, sem a mistificação burguesa, e, por conseguinte realiza a crítica na perspectiva marxiana. Por fim, fruto dessa análise de realidade, e ancorado nos "princípios orientadores" da teoria social marxiana realiza uma proposição alternativa da "transcendência"/superação das contradições postas pelo sistema do

${ }^{5}$ Cf.Tematização que pode ser apreendida pela leitura dos Capítulos 1, 3, 4, 5 e 6 de A Montanha..

\begin{tabular}{l|l|l|l|l|}
\hline Rovita Dialectus & Ano 2 & n.7 & Setembro - Dezembro 2015 & p. 48 - 67
\end{tabular}


capital, na perspectiva de uma sociedade socialista sustentável e que possa ser irreversível, sendo que essa postura crítica e propositiva ${ }^{6}$ permeia todo o texto.

Portanto, para consubstanciar sua "crítica radical do Estado", Mészáros não está movido pela mera imediaticidade de uma crise econômica conjuntural. Mas pela "urgência histórica" impulsionada pelo agravamento do quadro de sua análise de uma "época histórica" e desafiadora de "aprofundamento da crise estrutural do sistema do capital", abrangente, "sistêmica" e em "todas as dimensões da vida humana", no âmbito político, econômico, social, educacional, cultural, familiar, religioso, ecológico etc.

Aliás, o autor nos convida a olhar em nosso entorno e dizer qual dimensão da vida humana não está em crise profunda e que não seja regulada pelo Estado. Assim, é inegável que a crise atinge as principais instituições de reprodução da ordem social. Esta análise o autor apresenta-nos desde os anos de 1970 em A teoria da Alienação em Marx (2006), é aprofundada em Para Além do Capital: rumo a uma teoria da transição (2002), agrupa-se em A Crise Estrutural do Capital (2011) e está presente também no artigo Uma crise estrutural necessita de mudança estrutural (2011a). Chamamos a atenção do leitor para o alerta que o próprio autor, nas referidas obras, nos faz sobre a distinção fundamental, e não meramente acadêmica, entre uma crise periódica /conjuntural e a "crise estrutural do sistema do capital" (Mészáros, 2011a, p. 54 - 55), pois isso tem implicações para a esfera social, em suas estratégias de luta.

Retomamos o que mencionamos em Bitencourt (2013), que Mészáros tem procurado elucidar em sua produção teórica, três grandes ordens de desafios. A primeira que apresentanos (desde 2002, passando por seus outros títulos e comparece também neste de 2015) é sobre o desenvolvimento do sistema do capital, em sua "fase ascendente e descendente", que permite-lhe caracterizá-lo como um "modo singular" na história humana de "reprodução sociometabólica". Cuja conformação global, destrutiva, incontrolável entra em uma crise estrutural (MÉSZÁROS, 2015, p. 15 - 30), sistêmica, que ativa seus limites relativos e absolutos. (MÉSZÁROS, 2015, p. 18 - 19).

Estes limites são exemplificados por Mészáros (já em 2002 e alguns são retomados neste lançamento de 2015) através de quatro grandes contradições insolúveis na presente ordem: a) "o antagonismo entre o capital transnacional”, que atua em escala global, mas não possui o seu correspondente político - o Estado global - uma vez que as formações estatais constituíram-se em sua forma de Estado-nação (MÉSZÁROS, 2015, p. 80-81; 89; 104-106;

${ }^{6}$ Cf. Mais especificamente, o Capítulo 2, o Capítulo 7 e Apêndices. 
108-109); b) a produção destrutiva do ambiente natural (MÉSZÁROS, 2015, p. 95; 104; 111), imprescindível para a reprodução da vida humana; c) a incapacidade de responder ao desafio irreprimível da liberação das mulheres, da igualdade real, que permanece restrita às concessões formais/legais; d) o “desemprego estrutural”, (MÉSZÁROS, 2015, p. 98) com todas as suas mazelas sociais, diurnamente estampadas nos noticiários, e há muito, não só nas periferias, mas no centro do “capitalismo avançado". (MÉSZÁROS, 2002, p. 46 - 47).

A segunda ordem dos desafios é o chamamento de Mészáros (já desde, 2002, p. 50 e reaparece em 2015, p. 113 - 116) para a necessária autocrítica do movimento internacional da classe trabalhadora quanto ao reexame crítico da especificidade do sistema do tipo soviético. Sobre as experiências revolucionárias do século XX, Mészáros apresenta sua tese inédita, corajosa, inovadora, e que está longe de alcançar alguma unanimidade no movimento socialista, que caracteriza o modelo soviético como um "sistema do capital pós-capitalista", para ainda sentenciar que "absolutamente nada tinha em comum com o socialismo" original da elaboração marxiana.

Toda sua obra testemunha que, mesmo frente a esta constatação, sua análise não implica no abandono da perspectiva socialista, - como a "debandada" que acometeu muitos intelectuais da esquerda - e não demonstra a inviabilidade do pensamento marxiano - como tentaram outros tantos intelectuais. Ao contrário, Mészáros reafirma a radical proposição marxiana da necessidade de realizar uma revolução social, como condição para erradicar e superar o sistema de exploração do homem pelo homem. Pois, só essa em sua positividade é capaz de reerguer o edifício que deve ser demolido pela revolução política. Esta obviamente, constitui-se num primeiro e necessário passo, mas que, pelas próprias limitações intrínsecas à política em sua negatividade, pela sua parcialidade, é capaz apenas de negar o poder de comando alheio, e substituí-lo por outro, ainda assim, estranho à totalidade do corpo social.

É neste sentido que repõe a questão anteriormente indicada: "Quais são os requisitos de uma alternativa radicalmente diferente?" E se empenha ardorosamente em contribuir com a terceira ordem dos desafios postos à luta emancipatória. Desafio considerado por ele como uma demanda histórica das mais urgentes - diante do risco real, iminente e contínuo de destruição das condições da vida humana - que é elaborar os "princípios orientadores de uma teoria da transição socialista", para que a "tarefa histórica da classe trabalhadora", não incorra nos mesmos erros do passado e possa ser vitoriosa e sustentável. Assim, reafirma

a alternativa socialista está preocupada com a concepção geral e o estabelecimento prático de um modo qualitativamente diferente de intercâmbio social. Uma forma de intercâmbio em que as células

\begin{tabular}{|l|l|l|l|l|l|}
\hline Qovista Dialectus & Ano 2 & n.7 & Setembro - Dezembro 2015 & p. 48 - 67 \\
\hline
\end{tabular}


constitutivas ou os microcosmos do metabolismo social dado possam realmente ser coerentes em um todo historicamente sustentável. (MÉSZÁROS, 2015, p. 17).

Para tal, uma de suas teses centrais é como visualizar uma transição socialista que vá para além do capital, para além da "expropriação dos expropriadores" e "transceda"/ supere o tripé que sustenta a ordem do capital: o trabalho assalariado, o capital e o Estado. Como podemos perceber em todos esses grandes desafios, a problemática do Estado, como um componente indissociável do sistema do capital se faz presente. É, portanto, nesse quadro de referência que devemos inserir o desafio de hoje, apresentado por Mészáros, em A montanha que devemos conquistar, de realizar uma "crítica radical do Estado" e ao mesmo tempo como salienta o autor "a crítica só é viável se acarretar uma alternativa historicamente sustentável”.(MÉSZÁROS, 2015, p.16).

Nesta obra Mészáros (2015, p. 16) reafirma o Estado como um "órgão de comando global do capital", cuja "função vital" sempre foi atuar como "corretivo das estruturas antagônicas do sistema", "sempre foi a manutenção e também o fortalecimento dos irreprimíveis imperativos materiais de autoexpansão do sistema”. Assim, nosso desafio atual "exige uma crítica radical dos termos de referência fundamentais do Estado", uma vez que esta modalidade de tomada de decisão afeta a totalidade das funções reprodutivas da sociedade. Ainda mais frente à impossibilidade do Estado, como "órgão de controle do capital”, constituir-se em Estado global do capital, para além das rivalidades nacionais, numa era em que o poder do capital se manifesta de forma globalizada. (MÉSZÁROS, 2015, p. 89; 108-109).

Se o campo teórico-prático indicado por Mészáros, e auxiliado por essa metáfora, não é suficiente para esclarecer-nos, talvez devêssemos nos acercar de um alpinista que também sabe o que significa “conquistar uma montanha". Entende que para conquistá-la é preciso conhecê-la, escalá-la, chegar ao topo, ver o que tem lá e além dele, e que, no desafio da escalada, é fundamental depois de atingir o cume, desarmar o acampamento e fazer a escalada de volta, descer com vida e prosseguir. Isto requer resistência física e espiritual, materiais e conhecimentos adequados. Persistência e tenacidade para superar os obstáculos. Ou seja, é um desafio imenso e por mais que estejamos preparados, temos que fazer a escalada sem garantias totais de sucesso.

Mészáros analisa que muitos nem ousam fazer a escalada (como os reformistas que propõem apenas, mudanças graduais e não uma ruptura radical). Muitos morrem na escalada. Muitos desistem antes da vitória final. Muitos tomam caminhos errados, que não levam à

\begin{tabular}{|l|l|l|l|l|}
\hline Qevista Dialectus & Ano 2 & n.7 & Setembro - Dezembro 2015 & p. 48 - 67 \\
\hline
\end{tabular}


meta final (como testemunham os países que experimentaram as revoluções no século XX). Pois, não compreenderam que além de chegar ao topo (derrubar o poder capitalista), tem a caminhada de volta, que é descer do topo (erradicar o capital e restituir o poder aos "produtores livremente associados") e prosseguir com vida no novo relevo (de uma sociedade sem classes, e ancorada na "igualdade substantiva").

E mesmo frente a esses insucessos, muitos ainda continuam sonhando em fazer a escalada, muitos outros despertarão e ousarão novamente a experimentar a escalada. Pois uma montanha é sempre um convite à escalada, nos aguça saber como chegar lá, o que tem no topo e atrás dele. E as montanhas também têm sua formação, suas estruturas, suas fissuras, rachaduras, seus metamorfismos e dependendo de seus fundamentos, onde está assentada, pode desabar, pode ser explodida, ou ser "transcendida/superada".

Então a metáfora da "Montanha" aplicada a nossa realidade sócio histórica, com seus imensos desafios, que parecem ser intransponíveis, mas que precisam ser "transcendidos/superados", para prosseguirmos, sabendo o que tem lá no topo e para além dele, é uma boa metáfora, e é neste sentido que Mészáros a emprega. Como bem compreendeu Mascaro (2015, s/p) "a montanha a que Mészáros se refere como alvo a ser conquistado não é apenas o Estado e o campo político, mas a totalidade da sociabilidade capitalista" e, podemos ainda, referenciados em Mészáros, acrescentar que, o que precisa ser "transcendido"/superado é o próprio sistema do capital e todas as suas "mediações de segunda ordem".

Constatação que nos encaminha para a necessidade e possibilidade histórica de emancipar o trabalho do sistema do capital, e do seu órgão de comando político - o Estado. Mas a emancipação do trabalho só poderá ser vitoriosa se o Trabalho, em sua totalidade social, nortear-se pelos "princípios socialistas orientadores" de acordo com o projeto socialista genuíno ${ }^{7}$ de Marx. E de forma organizada internacionalmente atuar em conformidade com a Atualidade histórica da ofensiva socialista (2010) em um movimento que "não pode ser apenas um tipo de partido político orientado para a obtenção de concessões

\footnotetext{
${ }^{7}$ Esclarecemos que o uso do "adjetivo" "genúno" utilizado para caracterizar o projeto socialista marxiano, não deve ser desprezado e é constante em Mészáros. Seu significado não é apenas gramatical, embora mesmo esse seja esclarecedor, pois corresponde, conforme ao dicionário - ao que é verdadeiro; que não sofreu alterações ou falsificações; correto; puro; de sentido exato ou próprio - sinônimos: autêntico; fidedigno; real e verídico antônimos: falso; incorreto; mentiroso. Cf. Dicionário Online de Português. s/d. Disponível em: www.dicio.com.br. Acesso em: 08 set. 2015. A esse sentido gramatical, acrescenta-se o sentido teóricoprático, político, econômico, filosófico e cultural, utilizado por Mészáros, para diferenciar o projeto socialista original, tal como concebido por Marx, daqueles que se derivaram de seu pensamento, como no chamado "socialismo real", do tipo soviético e de sua área de influência. Até porque, na análise de Mészáros não houve "socialismo" nestes países que estivesse em conformidade com a concepção marxiana.
}

\begin{tabular}{|c|c|c|c|c|c|}
\hline Q & Anistalectus & Ano 2 & n.7 & Setembro - Dezembro 2015 & p. 48 - 67 \\
\hline
\end{tabular}


parlamentares". Mas sim, como um "movimento revolucionário de massas, ativo de maneira consciente em todas as formas de luta política e social: local, nacional e global/internacional". Acima de tudo, "sem medo de afirmar as demandas necessárias da ação extraparlamentar desafiadora”. (MÉSZÁROS, 2010, p. 43).

\section{PARA CONCLUIR NOSSAS REFLEXÕES}

Identificamos que Mészáros (2015, p. 111) considera que os desafios e obstáculos que "devemos escalar" para superar o atual sistema, em sua crise estrutural, são do tamanho de "muitos Himalaias um em cima do outro", pois o sistema em sua lógica expansionista procura deslocar suas contradições, até o limite em que puder perpetuar sua barbárie. Mas este pode levar a destruição de toda a humanidade (seja pelas guerras, pela destruição do ambiente necessário à reprodução da vida humana, ou pela produção destrutiva em si), ou pode e deve ser escalado, erradicado, "trancendido"/superado em sua totalidade e construída uma outra ordem social, cujo relevo seja acessível a todos, desde que sedimentado por uma "igualdade substantiva".

Então, até a metáfora, para ser entendida, tem que ser no "espírito do autor" que a elaborou, tem que ser analisada do ponto de vista do autor, da perspectiva adotada por ele. E, se mesmo assim, para nós brasileiros, a metáfora soa incômoda, ainda, resta-nos a própria obra, o texto do autor em si, que pode ser compreendido, pois tudo isto está expresso na obra de Mészáros.

Lembramos que Marx também gostava de utilizar-se de metáforas. E algumas delas remetem para os cumes e escaladas. Por exemplo, quando indicou-nos que "não há estrada real para a ciência e só têm possibilidade de chegar aos seus cumes luminosos aqueles que não temem fatigar-se a escalar as suas veredas escarpadas" (Marx, 1872, s/p). Quiçá não foi Marx que inspirou Mészáros em sua metáfora da Montanha. E quiçá continue a inspirar aqueles que verdadeiramente procurem orientar-se pelo projeto marxiano da emancipação humana via uma Revolução Social, que ponha abaixo A Montanha.

Pois, Mészáros, em toda a sua produção teórica, reafirma a proposição marxiana de que o socialismo implica em uma transformação total e global de todo o edifício societal, em que "os homens devem mudar de cima abaixo as condições de sua existência industrial e política, e consequentemente todo o seu modo de ser” (MARX, apud MÉSZÁROS, 2002, p. 215). Transformação essa, que é impossível via reformas e vai mais além do "expropriar os 
expropriadores". Segundo a síntese de Mészáros, emancipar o Trabalho implica em demolir todo o edifício, do tamanho de uma "montanha", em seu tripé: Trabalho assalariado, Capital e Estado, que usurpam do Trabalho o seu potencial humano criativo libertador.

Percebemos que o projeto teórico-prático de Mészáros constitui-se como um diferencial quanto ao ecletismo, conformismo e reformismo que impera no movimento internacional da classe trabalhadora, além de ser crítico ao divisionismo de sua ala radical. Filia-se entre aqueles que procuram de forma intransigente recuperar e propagar o caráter revolucionário da teoria social de Marx, por considerá-la apta a nos propiciar a compreensão do desenvolvimento sócio histórico e econômico, em seu próprio termo, o "sociometabolismo". Uma teoria que não é neutra, pois adota o ponto de vista de classe - do proletariado e da classe trabalhadora na sua totalidade, como o sujeito social da revolução socialista -, ou em termos categoriais, adota a perspectiva crítica do Trabalho, contra a perspectiva eternizadora e mistificadora do Capital e assegurada pelo seu ordenamento estatal.

Comumente, quando afirmamos que Mészáros filia-se à matriz teórica que apreende o estatuto ontológico da teoria social marxiana, cuja contribuição fundamental para essa elaboração é atribuída ao filósofo húngaro Lukács, de quem Mészáros foi assistente e amigo, até sua morte, logo nos dizem: então Mészáros é um lukacsiano!

Se essa denominação for um reconhecimento de que Mészáros foi capaz de apreender a grandeza da estatura filosófica e humana de Lukács, mas também o "ônus da sua responsabilidade moral enquanto intelectual" como reconhece Paulo Netto (2013, p. 13). Ou seja, segundo o mesmo, "Mészáros não é Lukács" (p. 16), embora a perspectiva críticometodológica de Mészáros lhe permite

agarrar a obra de Lukács na sua originalidade, destacar a sua monumentalidade e, no mesmo andamento perquiridor, apontar as suas tensões irresolutas e indicar a sua problematicidade, instaurando uma espaço de crítica a Lukács que, mantendo uma relação empática e simpática com sua obra, atinge de modo criativo e tendencialmente superador os seus fundamentos e o seu âmbito de validez. (PAULO NETTO, 2013, p. 14).

Se, se também considera as "severas notações críticas" que Mészáros (2013) realiza em $O$ conceito de dialética em Lukács, e nos capítulos 6 a 10 de Para além do capital (2002). Se for por considerar que, igualmente a Lukács, Mészáros foi capaz de empreender um retorno a Marx, por via de seus próprios textos, porque procuraram compreender o pensamento de Marx pelo próprio Marx. E se para tal, as fontes originais e fundamentais deste retorno foram o conjunto do texto marxiano da maturidade de $O$ Capital até aos iniciais da juventude, passando pelos Manuscritos Econômico- Filosóficos, nos quais Lukács apreende a

\begin{tabular}{|c|c|c|c|c|}
\hline Rovista Dialectus & Ano 2 & n.7 & Setembro - Dezembro 2015 & p. $48-67$ \\
\hline
\end{tabular}


matriz ontológica do pensamento de Marx. E Mészáros (2006) por seu turno a explicita, já em A teoria da alienação de Marx, e depois no conjunto de sua obra.

E se resgatar a radicalidade revolucionária da teoria marxiana que nos propicia vislumbrar a possibilidade e necessidade histórica de rumar "para além do capital", sem estancar em uma revolução política, que realiza apenas a "emancipação política" e, avançar para uma revolução social que realize a "emancipação humana", é ser lukácsiano - para usar uma expressão da moda - que sejamos todos lukácsianos! Mas que sejamos, também, tão marxianos quanto Mészáros. Pois, somos informados por Antunes (2009) que Mészáros, ao realizar uma profunda incursão no universo marxiano, constituiu sua própria vertente analítica de Marx, como ele mesmo a considera, culmina em uma "Ontologia singularmente Humana a partir do Trabalho".

Assim, convidamos aos leitores a escalarem a obra teórica de Mészáros, cujos “cumes luminosos" consubstanciam-se em vários outros títulos e em seu testemunho de vida. Desde que "não temem fatigar-se a escalar as suas veredas escarpadas", compreenderão a perspectiva ferrenhamente crítica e propositiva de Mészáros, principalmente frente à urgência do "desafio e fardo (de nosso) tempo histórico: (que clama pelo) socialismo no século XXI" (2007), cuja tarefa é imensa, do tamanho de uma Montanha que devemos conquistar (2015).

\section{REFERÊNCIAS}

ANTUNES, Ricardo. As formas de ser do trabalho, da alienação e da emancipação contemporâneas: Notas a propósito do Seminário Internacional István Mészáros. III Seminário Internacional Margem Esquerda: István Mészáros e os Desafios do Tempo Histórico. Mesa: Trabalho e alienação. 2009. Disponível em: <https://www.youtube.com/watch?v=3zf0N2W7V_I>. Acesso em: 08 set. 2015.

ANTUNES, Ricardo. Apresentação. In: Para Além do Capital: rumo a uma teoria da transição. Campinas: Boitempo, 2002. (Coleção Mundo do Trabalho).

BITENCOURT, Celeste Deográcias de Souza. Resenha: A natureza da crise contemporânea do capital e os desafios rumo a uma alternativa radical na obra de István Mészáros. Revista Trabalho \& Educação. Universidade Federal de Minas Gerais. Faculdade de Educação, n.0 (1996). Belo Horizonte: FaE/UFMG, v. 22, n. 2, mai./ago., p. 201-211. 2013. Disponível em: <http://www.portal.fae.ufmg.br/seer/index.php/trabedu/issue/view/90/showToc >. Acesso em: 08 de set. 2015.

CHASIN, José. Marx: estatuto ontológico e resolução metodológica. São Paulo/SP: Boitempo, 2009.

Dicionário Online de Português. Disponível em: www.dicio.com.br. Acesso em: 08 set. 2015.

\begin{tabular}{|c|c|c|c|c|}
\hline Rovista Dialectus & Ano 2 & n.7 & Setembro - Dezembro 2015 & p. $48-67$ \\
\hline
\end{tabular}


MARX, Karl. (1872) Prefácio à edição francesa de O Capital: crítica da economia política. Disponível em:

<https://www.marxists.org/portugues/marx/1867/capital/livro1/prefacios/04.htm\#i1 >. Acesso em: 08 de set. 2015.

MASCARO, Alysson Leando. [Orelha]. In.: A montanha que devemos conquistar: reflexões a cerca do Estado. São Paulo/SP: Boitempo, 2015.

MÉSZÁROS, István. A montanha que devemos conquistar: reflexões a cerca do Estado. São Paulo/SP: Boitempo, 2015.

A crise estrutural do capital. Trad. Francisco Raul Cornejo [et al.]. 2. ed. rev. e ampliada. São Paulo/SP: Boitempo, 2011.

A teoria da alienação em Marx. Trad. Isa Tavares. São Paulo/SP: Boitempo, 2006.

A atualidade histórica da ofensiva socialista: uma alternativa radical ao sistema parlamentar. Trad. Paulo Cezar Castanheira; Rev. Téc. Maria Orlanda Pinassi. São Paulo/SP: Boitempo, 2010.

Estrutura social e formas de consciência, volume II: a dialética da estrutura e da história. Trad. Rogério Berttoni; Rev. Téc. Caio Antunes. São Paulo/SP: Boitempo, 2011c. (Coleção Mundo do Trabalho).

O conceito de dialética em Lukács. São Paulo/SP: Boitempo, 2013.

O desafio e o fardo do tempo histórico: o socialismo no século XXI. São Paulo/SP: Boitempo, 2007.

O poder da ideologia. Trad. Paulo César Castanheira. São Paulo/SP: Boitempo. 2004. (Coleção Mundo do Trabalho).

Entrevista. Margem Esquerda: ensaios marxistas. São Paulo/SP: Boitempo, no 7, maio. p. 13-29. 2006a.

Reflexões sobre a Nova Internacional. Margem Esquerda: ensaios marxistas. São Paulo/SP: Boitempo, no 22: abr., p. 67-90. 2014.

. Uma crise estrutural necessita de mudança estrutural. Margem Esquerda: ensaios marxistas. São Paulo/SP: Boitempo, nº 17: nov., p. 53-68. $2011 \mathrm{a}$.

A Reconstrução necessária da dialética histórica. Trad. Raul Cornejo; Rev. Téc. Caio Antunes. In. JINKINGS, Ivana. \& NOBILIE, Rodrigo (Orgs.). Mészáros e os desafios do tempo histórico. São Paulo/SP: Boitempo, 2011 b.

Para Além do Capital: rumo a uma teoria da transição. Campinas: Boitempo Editorial, 2002. (Coleção Mundo do Trabalho). 
PAULO NETTO, José. Apresentação. In.: MÉSZÁROS, István. O conceito de dialética em Lukács. Trad. Rogério Bettoni. São Paulo/SP: Boitempo Editorial, 2013.

SOUZA JUNIOR, Hormindo Pereira de. As Origens da Ontologia do Ser Social: a questão do Método. Revista Trabalho \& Educação. Universidade Federal de Minas Gerais. Faculdade de Educação. Belo Horizonte: FaE/UFMG, v. 24, n.1, jan./abr. p. 143-155. 2015. Disponível em: <http://www.portal.fae.ufmg.br/seer/index.php/trabedu/issue/current/showToc >. Acesso em: 08 de set. 2015.

SOUZA JUNIOR, Hormindo Pereira de. Notas acerca de algumas questões filosóficas e de método em Durkheim, Weber e Marx: a afirmação da centralidade ontológica do trabalho na perspectiva marxiana. In. SOUZA JUNIOR, Hormindo Pereira de, LAUDARES, João Bosco. (Organizadores) Diálogos Conceituais sobre Trabalho e Educação. Belo Horizonte/MG:

Editora PUC Minas, $1^{\mathrm{a}}$ ed., p. 13-34. 2011.

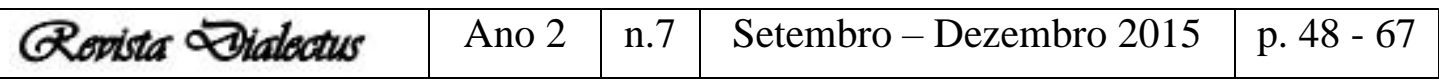

